\title{
DNA methylation and histone modifications as epigenetic regulation in prostate cancer (Review)
}

\author{
MARIA NOWACKA-ZAWISZA and EWELINA WIŚNIK \\ Department of Cytobiochemistry, Faculty of Biology and Environmental Protection, University of Lodz, 90-236 Lodz, Poland
}

Received March 15, 2017; Accepted July 24, 2017

DOI: $10.3892 /$ or.2017.5972

\begin{abstract}
Prostate cancer is the second most commonly diagnosed cancer in men in Poland after lung cancer and the third leading cause of cancer-related mortality after lung and colon cancer. The etiology of most cases of prostate cancer are not fully known, and therefore it is essential to search for the molecular basis of prostate cancer and markers for the early diagnosis of this type of cancer. Epigenetics deals with changes in gene expression that are not determined by changes in the DNA sequence. Epigenetic changes refer to changes in the structure of DNA, which are the result of DNA modification after replication and/or post-translational modification of proteins associated with DNA. In contrast to mutations, epigenetic changes are reversible and occur very rapidly. The major epigenetic mechanisms include DNA methylation, modification of histone proteins, chemical modification and chromatin remodeling changes in gene expression caused by microRNAs (miRNAs). Epigenetic changes play an important role in malignant transformation and can be specific to types of cancers including prostate cancer.
\end{abstract}

\section{Contents}

1. Introduction

2. DNA methylation and prostate cancer

3. Histone modifications and prostate cancer

4. Role of histone modification in the MDRl gene silencing in prostate cancer

5. Modifications of histones and proteins polycomb and Trithorax in the development of prostate cancer

6. Conclusion

Correspondence to: Dr Maria Nowacka-Zawisza, Department of Cytobiochemistry, Faculty of Biology and Environmental Protection, University of Lodz, Pomorska 141/143, 90-236 Lodz, Poland E-mail: maria.nowacka@biol.uni.lodz.pl

Key words: DNA methylation, epigenetics, histone modification, prostate cancer

\section{Introduction}

Prostate cancer (PC) is one of the most frequently diagnosed cancers in men. One cause for neoplastic transformation is abnormal gene expression, which is not determined by nucleotide sequence changes in DNA, but by disturbances in epigenetic mechanisms. The epigenetic changes in DNA structure are the result of post-replication modification in DNA and/or post-translational modification of proteins associated with DNA. In contrast to mutations, epigenetic modifications are reversible and dynamically occur. These epigenetic mechanisms include aberrant DNA methylation (hypermethylation and hypomethylation) and modifications of histones, chromatin remodeling and changes in gene expression caused by non-coding RNAs (ncRNAs). Epigenetic mechanisms lead to genomic instability and inappropriate gene expression and are the best-characterized alteration in PC. Epigenetic mechanisms play an important role in the initiation and development of PC. Global and gene-specific hypermethylation and hypomethylation as well as histone modifications have been found to be associated with PC $(1,2)$.

\section{DNA methylation and prostate cancer}

DNA methylation plays an important role in DNA repair, recombination and replication, as well as regulation of gene activity. DNA methylation involves the addition of a methyl group to the 5'-carbon of cytosine in $\mathrm{CpG}$ dinucleotide sequences. This process is catalyzed by a family of DNA methyltransferases (DNMTs). $\mathrm{CpG}$ islands are $\mathrm{CpG}$-rich areas of $200 \mathrm{bp}$ to several kilobases in length, usually located near the promoters of highly expressed genes, and are the sites of common methylation in human tumors, including the prostate. $\mathrm{CpG}$ islands, in more than $55 \%$ of cases, form clusters and their methylation/demethylation results in the inhibition/activation of transcription. Thus, methylation of $\mathrm{CpG}$ islands in promoter regions of genes may prevent or deregulate the synthesis of gene products (3-5).

Three active DNMTs have been identified (DNMT1, DNMT3A and DNMT3B). A fourth enzyme previously known as DNMT2 is not a DNA methyltransferase. DNMT2 or TRDMT1 has strong sequence similarities with 5-methylcytosine methyltransferases, but the enzyme was shown to methylate position 38 in aspartic acid transfer RNA and does not methylate DNA. The smallest mammalian DNMT2 


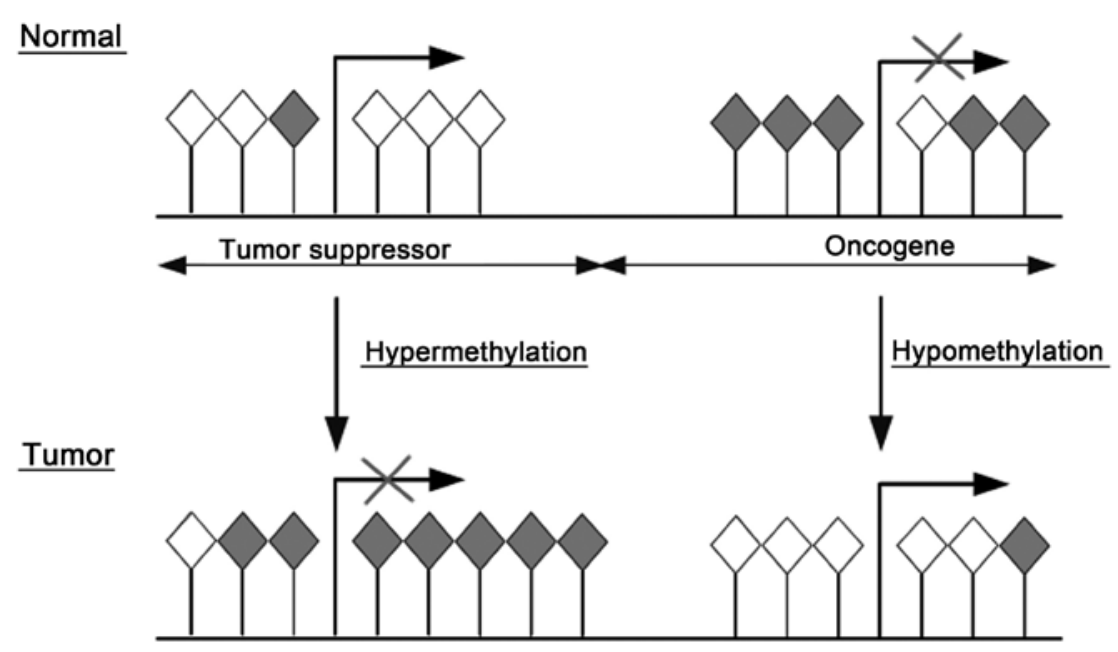

Figure 1. Role of DNA methylation in cancer (9).

is believed to participate in the recognition of DNA damage, DNA recombination and mutation repair. DNMT1, the major enzyme responsible for maintenance of the DNA methylation pattern is located at the replication fork and methylates newly biosynthesized DNA. DNMT3A and DNMT3B cannot differentiate between unmethylated and hemi-methylated $\mathrm{CpG}$ sites, and they cannot copy a specific pattern of methylation or contribute to the maintenance of the methylation pattern (6).

Proteins that bind to methylated $\mathrm{CpG}$ islands (MBP, methyl-CpG binding proteins) which include: MBP1, MBP2, MBP3 and methyl CpG-binding protein-2 (MeCP2) recognize methylated $\mathrm{CpG}$ islands in the promoter regions of the genes. These proteins at the $\mathrm{N}$-terminal contain methyl-CpG-binding domain (MBD) and in the central portion transcriptional repression domain (TRD). MBP proteins can activate histone deacetylase (HDAC), and/or co-repressors of transcription, after recognizing methylated DNA. Then, chromatin undergoes strong condensation, preventing access of transcription factors to the promoter's genes (7).

Disturbances of DNA methylation can lead to malignant transformation. In PC, hypermethylation and hypomethylation of DNA can be observed. In normal cells, $\mathrm{CpG}$ islands are protective against excessive methylation by active transcription, DNA demethylation, regulation of replication and the establishment of appropriate local chromatin structure, impeding access to methyl-DNA transferase. In tumor cells, the mechanisms as described above are altered, resulting in abnormal DNA methylation regulation $(2,8)$.

A common molecular feature associated with tumorigenesis including PC is hypermethylation of cytosines $5^{\prime}$ in $\mathrm{CpG}$ islands within the regulatory (promoter) region of suppressor genes resulting in gene silencing. In contrast, hypomethylation in the promoter region of oncogenes in tumors reactivates transcription (Fig. 1). Moreover, 5-methyl cytosine is unstable and mutates to thymine and methylated $\mathrm{CpG}$ sites degrade to TpG/CpA (9).

DNA hypermethylation. In $\mathrm{PC}$, many $\mathrm{CpG}$ islands exhibit aberrant hypermethylation. Genes undergoing methylation in $\mathrm{PC}$ include genes involved in key cellular functions such as DNA repair (GSTPI and $M G M T)$, cell adhesion $(C D H 1$ and
$C D 44)$, cell cycle control (CDKN2A), apoptosis (PYCARD) and also are related to suppressor genes $(A P C, R A R \beta, R A R R E S 1$ and $R A S S F 1)(5,8,10)$. Specific genes implicated within each category are summarized in Table I.

The glutathione S-transferase $\pi 1$ gene (GSTPl) encodes glutathione $S$-transferase belonging to the $\pi$ class. It is responsible for protecting cells from oxidative stress and chemical attacks. GSTP1 is involved in the metabolism, detoxification and elimination of compounds potentially genotoxic, and prevents DNA damage and initiation of neoplastic transformation. GSTP1 is one of the earliest identified genes which is hypermethylated in PC. GSTP1 hypermethylation has been found in $13.3-100 \%$ of PC cases, whereas methylation of GSTPI within CpG dinucleotides has not been noted in normal cells. GSTP1 hypermethylation is present at all stages of PC development, and the assessment of the methylation profile of this gene allows the differentiation of types and subtypes of PC which may facilitate early diagnosis. GSTPl gene methylation profile can be assessed not only in serum but also in other body fluids. In $39-83.2 \%$ of PC patients, GSTP1 DNA methylation was detected in urine $(11,12)$. Hypermethylation of GSTP1 DNA was detected in plasma samples from 27 of 31 (92.86\%) patients with PC (13). Methylated GSTP1 DNA in serum is present in $28-32 \%$ of men with metastatic PC $(14,15)$. Mahon et al (16) identified plasma methylated GSTP1 DNA as a potential prognostic marker in men with castration-resistant $\mathrm{PC}$ as well as a potential surrogate therapeutic efficacy marker for chemotherapy.

The O-6-methylguanine-DNA methyltransferase gene $(M G M T)$ encoding enzyme removes alkyl adducts from the O6 position of guanine. Methylation of the $M G M T$ gene promoter region has been detected in $\mathrm{PC}$ patients and cell lines (17-19). DNA hypermethylation of $\mathrm{CpG}$ dinucleotides of the MGMT gene has been associated with decrease and/or total loss of expression of this gene, and results in the development of carcinoma. A study conducted by Sidhu et al (18) indicated that development of prostate carcinoma is correlated with modification of the MGMT methylation pattern.

PC tumor cell invasion and progression have been found to be associated with E-cadherin-1 ( $\mathrm{CDH}$ ) gene promoter hypermethylation. The effect of increased methylation of 
Table I. Genes hypermethylated in prostate cancer.

\begin{tabular}{|c|c|c|c|c|}
\hline Gene & $\begin{array}{l}\text { Chromosomal } \\
\text { location }\end{array}$ & Function & $\begin{array}{l}\text { Hypermethylation in } \\
\text { prostate cancer }(\%)\end{array}$ & Refs. \\
\hline GSTP1 & $11 q 13$ & Detoxification, DNA repair & $13-100$ & $(13,16,72-82)$ \\
\hline$M G M T$ & $10 q 26$ & Detoxification, DNA repair & $0-76$ & $(17-19,35)$ \\
\hline $\mathrm{CDH1}$ & $16 q 22.1$ & Cell adhesion & $0-72$ & $(22,29,83)$ \\
\hline$C D 44$ & $11 \mathrm{p} 13$ & $\begin{array}{l}\text { Cell-cell interactions, cell adhesion and } \\
\text { migration }\end{array}$ & $20-78$ & $(21,23,84)$ \\
\hline$C C N D 2$ & $12 \mathrm{p} 13$ & $\begin{array}{l}\text { Regulation of cyclin-dependent protein } \\
\text { serine/threonine kinase activity }\end{array}$ & 8.4-99 & $(19,73,75)$ \\
\hline$A P C$ & $5 q 21-q 22$ & $\begin{array}{l}\text { Tumor suppressor; antagonist of the Wnt } \\
\text { signaling pathway; regulator of cell migration, } \\
\text { adhesion, transcriptional activation and apoptosis }\end{array}$ & $14.5-100$ & $\begin{array}{l}(19,27,75,76 \\
80,82,85-87)\end{array}$ \\
\hline$R A R \beta$ & $17 q 21$ & $\begin{array}{l}\text { Tumor suppressor; regulation of development, } \\
\text { differentiation, apoptosis, granulopoeisis, } \\
\text { and transcription of clock genes }\end{array}$ & $32.6-100$ & $(19,73,75-77)$ \\
\hline RASSF $1 A$ & $3 \mathrm{p} 21.3$ & $\begin{array}{l}\text { Tumor suppressor; } \\
\text { Ras protein signal transduction }\end{array}$ & $19.2-100$ & $(19,72,73,86)$ \\
\hline
\end{tabular}

GSTP1, glutathione-S-transferase $\pi$ 1; MGMT, O-6-methylguanine-DNA methyltransferase; $C D H 1$, E-cadherin-1; $C D 44$, CD44 molecule; $C C N D 2$, cyclin D2; $A P C$, adenomatous polyposis coli; $R A R \beta$, retinoic acid receptor $\beta ; R A S S F 1 A$, Ras-associated domain family member 1 .

$C D H 1$ is a decrease in E-cadherin expression, which is one of the main factors associated with dysfunction of intercellular adhesion, inhibition of cell adhesion and promotion of neoplastic transformation and metastasis $(5,20)$.

The CD44 gene which encodes cluster of differentiation CD44 may be another important mediator of prostate carcinogenesis, since it is hypermethylated in $78 \%$ of patients with PC in compared to only $10 \%$ of patients without cancer. Based on the morphology of fibroblasts, increased $C D 44$ gene promoter hypermethylation was found to be a characteristic feature of epithelial-to-mesenchymal transition (EMT) in non-prostate malignant tumors $(8,21-23)$.

The cyclin D2 (CCND2) gene encodes a protein belonging to the conserved family of cyclin $\mathrm{D}$, which are characterized by cyclic occurrence in the cell. Cyclins D form complexes with cyclin-dependent kinases CDK4 and CDK6. These complexes regulate cell cycle transition from $\mathrm{G} 1$ to $\mathrm{S}$ phase. CCND2 gene hypermethylation was found in $32 \%$ of PC cases which was significantly higher as compared to the hypermethylation noted in $6 \%$ of nonmalignant prostate tissues. In addition, high levels of CCND2 methylation were found to correlate with tumor aggressiveness $(8,24)$. In a study by Henrique et al $(25)$, cyclin D2 promoter methylation was found in $80 \%$ of benign prostatic hyperplasia (BPH), in $99.2 \%$ of PC and in $100 \%$ of high-grade prostatic intraepithelial neoplasia.

PYCARD also known as the target of methylation induced silencing 1 (TMS1) gene, encodes a proapoptotic protein, which contains a pyrin domain (PYD) in the $\mathrm{N}$-terminus and caspase recruitment domain (CARD) in the $\mathrm{C}$-terminus. Both domains are members of the death domain-fold superfamily. PYCARD plays an important role in the development of many diseases, including cancer. It is considered that PYCARD induces apoptosis via caspase 9. Hypermethylation of PYCARD is a common event in PC, and decreased PYCARD expression has been associated with complete methylation of the promoter region in human prostate carcinoma cell line LNCaP (26).

The adenomatosis polyposis coli $(A P C)$ gene encodes a protein that is involved in the regulation of many cellular processes including division, migration, adhesion and differentiation of cells. Promoter methylation in the $A P C$ gene has been associated with high grade and advanced stages of PC $(27,28)$.

The retinoic acid receptor $\beta(R A R \beta)$ gene encodes $\beta$ retinoid acid (RA) receptor, which forms complexes with two nuclear receptor families i.e. retinoid acid receptors ( $\mathrm{RAR} \alpha$, $\beta$ and $\gamma$ ) and $\mathrm{X}$ retinoid receptors $(\operatorname{RXR} \alpha, \beta$ and $\gamma)$. Retinoid acid belongs to the retinoids which induce numerous cellular pathways involving kinases responsible for activation or inhibition of transcription of many genes. A study conducted by Jerónimo et al (29) showed that $R A R \beta 2$ is hypermethylated in $97.5 \%$ of PC and in $94.7 \%$ of prostate intraepithelial neoplasia (PIN), while only in $23.3 \%$ of BPH. Thus, hypermethylation of genes encoding retinoid receptors may cause changes in their expression, which can affect PC progression.

The retinoic acid receptor responder gene 1 (RARRESI) also known as tazarotene-induced gene 1 (TIGl) was first identified as a gene responsive to retinoic acid. Decreased levels of RARRES1 expression have been demonstrated in PC. Furthermore, it has been suggested that RARRES1 gene silencing may be a consequence of receptor binding retinoid RAR $\beta$ methylation and is correlated with PC progression. Decreased RARRESI expression affects cell-cell interactions and results in increased proliferation and invasiveness of tumor cells. Loss of RARRES1 expression may explain the low sensitivity to retinoid-induced growth regulation $(30,31)$.

Ras-associated domain family 1 (RASSF 1$)$ is a putative tumor-suppressor gene (TSG) located in the chromosomal 
Table II. Genes hypomethylated in prostate cancer.

\begin{tabular}{lllcr}
\hline Gene & $\begin{array}{c}\text { Chromosomal } \\
\text { location }\end{array}$ & \multicolumn{1}{c}{ Function } & $\begin{array}{c}\text { Hypermethylation in } \\
\text { prostate cancer }(\%)\end{array}$ & Refs. \\
\hline uPA, PLAU & $10 \mathrm{q} 22.2$ & $\begin{array}{l}\text { Blood coagulation, fibrinolysis, } \\
\text { hemostasis, plasminogen activation }\end{array}$ & $23.2-96.6$ & $(88,89)$ \\
HPSE & $4 \mathrm{q} 21.3$ & Cell adhesion & $8.5-30$ & $(43)$ \\
CYP1B1 & $2 \mathrm{p} 22.2$ & Oxidation & $5.7-17.1$ & $(44)$ \\
WNT5A & $3 \mathrm{p} 21-\mathrm{p} 14$ & Cell signaling & 65 & $(45)$ \\
SIOOP & $4 \mathrm{p} 16$ & Cellular calcium signaling & 50 & $(45)$ \\
CRIP1 & $14 \mathrm{q} 32.33$ & Cellular repair and intracellular zinc transport & 65 & $(45)$ \\
\hline
\end{tabular}

uPA, PLAU, urokinase plasminogen activator; HPSE, heparanase; CYP1B1, cytochrome P450 family 1 subfamily B member 1 ; WNT5A, wingless-related MMTV integration site 5A; S100P, S100 calcium-binding protein $\mathrm{P}$; CRIP1, cysteine-rich protein 1.

region 3p21.3. RASSF1 is functionally associated with cell cycle control, microtubule stabilization, cellular adhesion, motility and apoptosis. Hypermethylation of RASSF1A is not specific to PC and has been identified in $35.5-96 \%$ of various cancers (32-34). Hypermethylation of RASSFIA in $53 \%$ of PC cases was found to be associated with a higher level of prostate-specific antigen (PSA) and aggressive PC. The effects of changes in the expression of RASSF1A include disturbances of the cell cycle and cell proliferation (35). A meta-analysis suggested that RASSF1A promoter methylation is significantly associated with PC risk and its clinicopathological variables (Gleason score, serum PSA level and tumor stage) (36).

However, Pellacani et al (37) suggested that for a set of genes (including GSTPI) that are hypermethylated in PC, gene downregulation appears to be the result of cell differentiation and is not cancer-specific. Hypermethylation is observed in more differentiated cancer cells and is promoted by hyperproliferation. These genes are maintained as actively expressed and methylation-free in undifferentiated PC cells, and their hypermethylation is not essential for either tumor development or expansion.

DNA hypomethylation. The mechanism leading to hypomethylation of DNA in cancer is not fully understood. Many studies have suggested diverse causes for the hypomethylation of DNA, including shortages of S-adenosylmethionine precursors or folic acid in the diet or genetic abnormalities in the metabolic pathway of the donor of methyl groups. DNA hypomethylation can also be attributed to a deficiency in methyltransferases. Hypomethylation in promoter regions of genes can lead to a reduction in genome stability through an increase in the expression of transposons, which under physiological conditions are silenced by methylation. Reduction in methylation may also cause a reduction in chromosomal stability and activation of proto-oncogenes $(3,5)$.

Hypomethylation of DNA is more often observed at metastasis than in the early stages of neoplastic transformation in PC. Hypomethylation in PC is observed among repetitive sequences of LINE-1 (long interspersed nuclear element-1), which is found in $64 \%$ of cases of advanced PC with metastases to lymph nodes $(38,39)$.
Reduction in the level of methylation of the genome reduces the stability of chromosomes leading to activation of the proto-oncogene MYC (homolog of viral myelocytomatosis oncogene) and RAS (homolog of viral rat sarcoma oncogene). A strong correlation between overexpression of protooncogene MYC in PC, and increased degree of invasiveness of the tumor has been shown. Hypomethylation of promotor regions of proto-oncogenes contributes to the activation and overexpression of their products, and thus excessive cell proliferation $(8,40)$.

In $\mathrm{PC}$, hypomethylation and higher expression of several genes, among them PLAU, HPSE or CYPIB1 have been identified (Table II).

Urokinase plasminogen activator (uPA; PLAU) plays a key role in tissue degradation, cell migration, angiogenesis, cancer invasion and metastasis. UPA is a member of the serine protease family and is strongly implicated as a promoter of tumor progression in various human malignancies. It is synthesized and secreted as a pro-enzyme, whose activation is markedly accelerated upon binding to specific membrane-bounded or soluble cell surface uPA receptors (uPARs). Binding to UPAR, uPA efficiently converts the inactive zymogen, plasminogen, into the active serine protease, plasmin, which then directly or indirectly cleaves extracellular matrix components including laminin, fibronectin, fibrin, vitronectin and collagen $(41,42)$. The link between the hypomethylation of the PLAU gene and alterations in chromosome 10 and the invasiveness and metastasis of different cancers has been confirmed, including $\mathrm{PC}(5,8)$.

Heparanase (HPSE), an endo- $\beta$-D-glucuronidase, can cleave the heparan sulfate chain of heparan sulfate proteoglycans, and is actively involved in the process of extracellular matrix degradation. Heparanase activity is detectable in platelets, neutrophils, activated $\mathrm{T}$ lymphocytes, and various malignancies including PC. Hypomethylation of the HPSE gene has been identified in 8.5-30\% of PC cases (43).

Cytochrome P450s are a multigene family of constitutively expressed and inducible enzymes involved in the oxidative metabolic activation and deactivation of carcinogens and cancer therapeutics. Cytochrome P450 1B1 (CYP1B1) is encoded by a member of the CYP1 gene family CYP1B1 and is one of the major enzymes involved in the hydroxylation 
of estrogens and activation of potential carcinogens. CYP1B1 has been found to be hypomethylated in $5.7-17.1 \%$ of PC cases (44).

Wingless-related MMTV integration site 5A (WNT5A), S100 calcium-binding protein P (S100P) and cysteine-rich protein 1 (CRIP1) genes are also found to be hypomethylated in primary PC tissues. The encoded proteins similarly as other hypomethylated genes are associated with tumorigenesis and metastasis $(3,45)$.

WNT5A activates the WNT/ $\beta$-catenin-independent pathway and its overexpression is associated with tumor aggressiveness enhancing invasive activity. For this action, WNT5A-induced receptor endocytosis with clathrin is required. WNT5A promotes the aggressiveness of PC and its expression is involved in relapse after prostatectomy $(46,47)$.

S100P protein regulates calcium signal transduction and mediates cytoskeletal interaction, protein phosphorylation and transcriptional control. It is suggested that S100P could be considered as a potential drug target or a chemosensitization target, and could also serve as a biomarker for aggressive, hormone-refractory and metastatic PC (48).

Cysteine-rich intestinal protein 1 (CRIP1) belongs to the LIM/double-zinc finger protein family and has been shown to be overexpressed in several tumor types, including breast, endometrial and prostate $(45,49,50)$.

\section{Histone modifications and prostate cancer}

Histones are highly conserved alkaline proteins that can become post-translationally modified at amino acid residues located on their $\mathrm{N}$ - and $\mathrm{C}$-terminal tails. There are four core histones: histone 2A (H2A), histone 2B (H2B), histone 3 (H3) and histone $4(\mathrm{H} 4)$, and one linker histone, histone $1(\mathrm{H} 1)$. Approximately 146/7 base pairs of DNA are wound around each histone octamer, which consists of two copies of each of the core histones, in left-handed superhelical turns (51).

Modifications involving covalent attachment/detachment of the molecules or functional groups to the N-terminal tails of histone contribute to changes of chromatin structure. The main histone modifications include: methylation, acetylation and phosphorylation. Changes in chromatin structure are the result of the remodeling caused by looseness, shifting nucleosomes along the DNA and/or replacement of histones comprising the nucleosome core. Post-translational modifications of histones play an important role in the organization of chromatin structure, particularly in the homeostasis between euchromatin, transcriptionally active and heterochromatin, transcriptionally inactive. Histone modifications can lead to activation or repression of gene expression, depending on the type and position of attached functional groups and amino acid residues which are modified $(2,51)$.

In tumor cells, changes in the pattern of the modification and genomic location of modified histone occur. These alterations overlap in the early stages of tumorigenesis and accumulate as the disease progresses. Changes in the pattern of histone modification in the promoter sequences may be the cause of altered gene expression by activation of oncogenes and TSG repression. These mechanisms may contribute to oncogenesis through upregulation of transcription, replication, DNA repair or cell cycle progression $(51,52)$.
Histone acetylation. Acetylation is a key histone modification and introduction of an acetyl group to the lysine residues of the histone tail. Histone acetyltransferases (HATs) and histone deacetylases (HDACs) are a family of enzymes that acetylate/deacetylate the histone tails of the nucleosome. Linking these reversible modifications with changes in gene expression contribute to the recognition of HATs as co-activators and HDACs as co-repressors of transcription. Mutations in genes encoding the above-mentioned enzymes may result in neoplastic transformation (2).

In prostate tumor cells, increased activity of HDACs, and particularly isoforms HDAC1, HDAC2, and HDAC3, which is correlated with elevated serum PSA levels and with increased invasiveness of tumor cells has been observed. In cancer therapy, HDAC inhibitors of the activity of HDACs are used to inhibit proliferation and induce differentiation or apoptosis of neoplastic cells. Hyperacetylation resulting from treatment with HDAC inhibitors has been observed in both normal and neoplastic cells; however, proapoptotic and antiproliferative activity is increased in tumor cells. In addition, studies have demonstrated a lower level of serum PSA in patients who were treated with HDAC inhibitors. HDAC inhibitors activate transcription of the gene encoding the protein $\mathrm{p} 21$, which is an inhibitor of cyclin-dependent kinases, and simultaneously inhibits expression of cyclins D1, A and E. The presence of p21 protein affects cell cycle arrest at the $\mathrm{G} 1$ phase or $\mathrm{G} 2 / \mathrm{M}$ in tumor cells $(1,2,8)$.

Histone methylation. Histone methylation is a modification catalyzed by histone methyltransferase (HMT) carrying a methyl group $\left(-\mathrm{CH}_{3}\right)$ derived from $\mathrm{S}$-adenosylmethionine (SAM) on a lysine or arginine residue. Methyl groups from lysine or arginine residues are removed by histone demethylase (HDM). For the lysine residue in histone mono-, di- and trimethyl groups may be attached. The methylation of histones is associated with activation, as well as repression of gene expression, depending on the position of amino acid residues in a protein and the level of methylation $(53,54)$.

In PC cells, reduced levels of histone 3 lysine 4 trimethylation (H3K4me3), and histone 3 lysine 18 monoacetylation (H3K18Ac) are observed. Low levels of these two modifications in patients with $\mathrm{PC}$ are negative prognostic indicators as well as indicators of an increased risk of relapse in comparison with patients with high levels of these modifications. Elevated levels of histone 3 lysine 9 and 18 monoacetylation (H3K9Ac, $\mathrm{H} 3 \mathrm{~K} 18 \mathrm{Ac}$ ) and histone 3 lysine 4 dimethylation (H3K4me2) allow discrimination between normal and PC cells $(51,53)$.

Phosphorylation of histones. Phosphorylation of histones is catalyzed by a number of kinases such as the cyclin-dependent kinases, called mitogen- and stress-activated protein kinase (MSK) and the kinase Aurora B. Phosphorylation is closely associated with the cell cycle. Most phosphorylation take place on histone 3 serine residues at position 10 and 28, as well as threonine residue at positions 3,6 and $11(55,56)$.

DNA double-strand breaks which may lead to chromosomal aberrations and/or apoptosis contribute to the phosphorylation of serine residue at position 139 of histone subtype $2 \mathrm{~A}$, called $\mathrm{H} 2 \mathrm{AX}$. The phosphorylated form of histone $\mathrm{H} 2 \mathrm{AX}$ is termed $\gamma \mathrm{H} 2 \mathrm{AX}$. Histone $\mathrm{H} 2 \mathrm{AX}$ phosphorylation is catalyzed 
by protein kinase ataxia teleangiectasia mutated (ATM) and DNA-dependent protein kinase (DNA-PK) which belong to the family of phosphatidylinositol 3-kinase-related protein kinases (PI3KK/PIKK kinases). Histone $\gamma \mathrm{H} 2 \mathrm{AX}$ causes relaxation of chromatin and thereby facilitates the accumulation of repair factors at the site of damage. Nanni et al (57) demonstrated the presence of histone $\gamma \mathrm{H} 2 \mathrm{AX}$ at different stages of PC. Detailed knowledge of the function of histone H2AX may be important for the diagnosis of cancers, including PC and tumor therapy $(2,55,58,59)$. In PC, overexpression of histone $\mathrm{H} 2 \mathrm{AZ}$, which is a variant of histone 2A was observed (60). $\mathrm{H} 2 \mathrm{~A} . \mathrm{Z}$ is also associated with androgen receptor (AR) gene transactivation and progression of PC. In PC histone $2 \mathrm{AZ}$ is ubiquitinated in K120, K121 and K125 and is associated with transcriptional silencing (61).

Recent studies have attempted to determine the relationship between the activity of the proliferation marker Ki-67 (Kiel) in PC, and the level of phosphorylation of histone H3. The expression of Ki-67 protein was found in all cell cycle phases except G0 phase, whereas the phosphorylation of histone H3 was identified only in $\mathrm{G} 2$ phase and mitosis. One study showed a higher frequency of phosphorylation of histone H3 in PC, compared to BPH. Furthermore, histone $\mathrm{H} 3$ phosphorylation in PC was found to correlate with the proliferation index and expression of the Ki-67 protein and the level of serum PSA (62).

\section{Role of histone modification in MDR1 gene silencing in prostate cancer}

Multidrug resistance receptor $1(M D R I)$ gene encodes a transmembrane P-glycoprotein (P-gp), which is an ATP-dependent transporter. P-glycoprotein plays an important role in the removal of xenobiotics captured in the cell membrane and their removal outside of the cell, which in the case of tumor cells determines their resistance to the chemotherapeutic agents used. MDRI promoter methylation is common in prostate carcinoma. However, studies indicate no correlation between MDR1 gene promoter methylation and reduced transcription of the gene in the early stages of carcinogenesis while post-translational modifications of histones appear to be the primary mechanism for suppression of the MDRl gene. MDR1 promoter methylation and P-gp expression in $121 \mathrm{PC}$, 39 high-grade prostatic intraepithelial neoplasia (HGPIN), $28 \mathrm{BPH}$ and 10 morphologically normal prostate tissue (NPT) samples were studied, using quantitative methylation-specific PCR and immunohistochemistry, respectively. PC cell lines were exposed to a DNMT inhibitor, 5-aza-2'deoxycytidine (DAC), and histone deacetylase inhibitor trichostatin A (TSA). Methylation and histone post-transcriptional modification statuses were characterized and correlated with mRNA and protein expression. MDRI promoter methylation levels and frequency were significantly increased from NPTs, to HGPIN and to PC. Conversely, decreased or absent P-gp immunoexpression was observed in HGPIN and PC, inversely correlating with methylation levels. Exposure to DAC alone did not significantly alter methylation levels, although increased expression was apparent. However, P-gp mRNA and protein re-expression were higher in cell lines exposed to TSA alone or combined with DAC. Accordingly, histone active markers

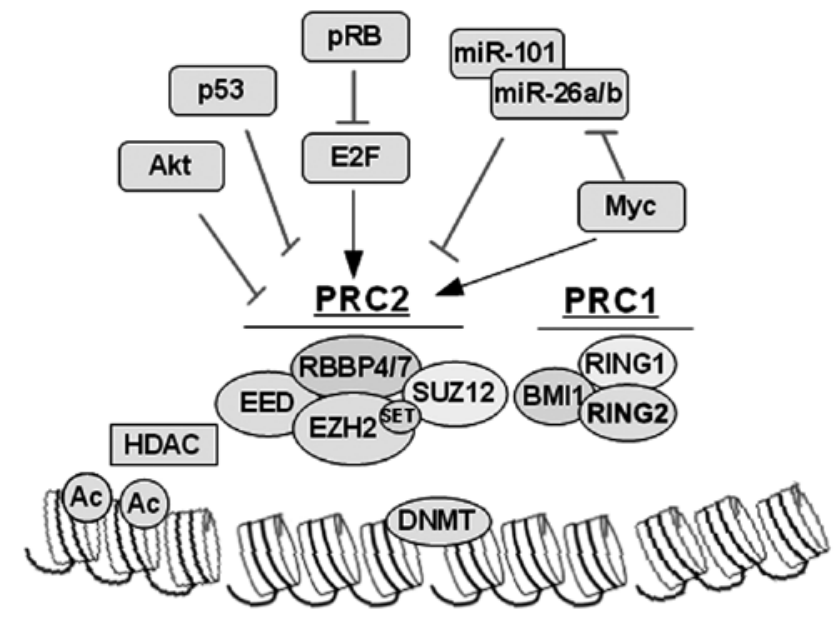

Figure 2. EZH2 histone methyltransferase as an epigenetic silencer of tumorsuppressor genes in prostate cancer (64).

H3Ac, H3K4me2, H3K4me3, H3K9Ac and H4Ac were increased at the MDRl promoter after exposure to TSA alone or combined with DAC (63).

\section{Modifications of histones and proteins polycomb and Trithorax in the development of prostate cancer}

Polycomb group $(\mathrm{PcG})$ proteins as well as trithorax group (TrxG) proteins have been discovered to cooperatively maintain the desirable histone patterns by methylating the histone tails for precise gene expression in various cellular processes. Playing opposing roles although both act to modify lysine residues within histone tails, activities of the PcG proteins are associated with repression of transcription while those of Trx proteins are associated with enhancement (64).

PcG proteins form repressive complexes (PRCs). One of them is the mammalian PRC1 complex consisting of the following proteins: three $\mathrm{Ph}$ homologues [polyhomeotic-like protein 1 (PHC1), PHC2 and PHC3], five Pc homologues [chromobox protein homologue 2 (CBX2), CBX4, CBX6, CBX7 and CBX8], two Psc homologues (BMI1 and MEL18) and four other polycomb group RING finger proteins (PCGFs) (65). Mammalian PRC2 complexes contain the direct homologues enhancer of zeste called homologue 2 (EZH2) (or, in some cases, EZH1), embryonic ectoderm development (EED), suppressor of zeste called 12 proteins (SUZ12) and RBBP4 and RBBP7 (histone-binding protein, also known as retinoblastoma associated protein 46 and 48 RBAP48 and RBAP46). $\mathrm{PcG}$ repressor complexes inactivate specific regions of chromatin, inhibiting transcription by specific modification of histone tails, then recognized by specific effector proteins (65-67).

EZH2 catalyzes trimethylation of the histone $\mathrm{H} 3$ at lysine 27 and is the enzymatic member of the polycomb repressor complex PRC2. In addition, EZH2 induces chromatin compaction and epigenetic silencing of key TSGs in cooperation with PRC1, HDAC and DNMT, which subsequently result in tumorigenesis and metastasis. EZH2 itself can be regulated post-translationally (by Akt-mediated phosphorylation), post-transcriptionally (by microRNAs), and through multiple 
A
CDK $1 / 2$
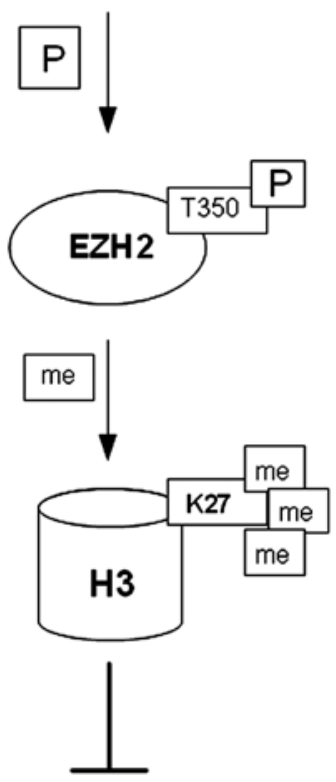

Tumor

suppressor

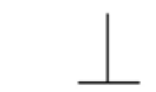

Tumor migration and proliferation
B

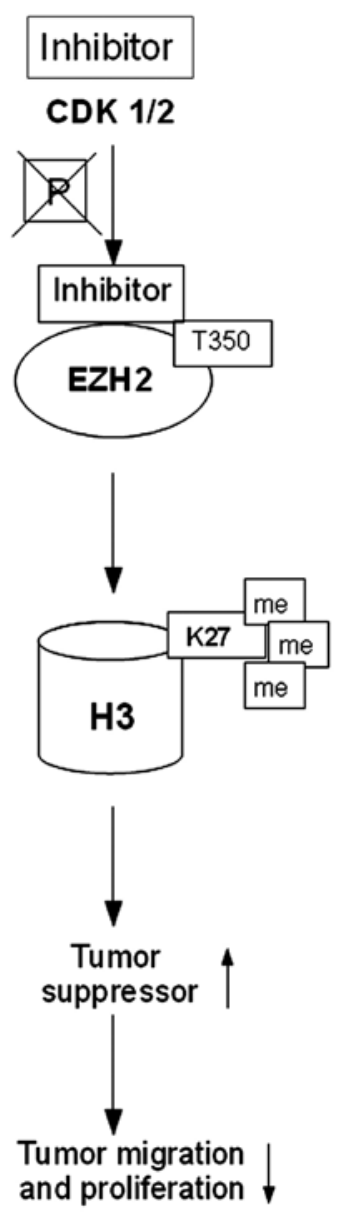

Figure 3. Invasiveness of tumor cells in the case of (A) activation or (B) inactivation of EZH2 histone methyltransferase (8).

pathways transcriptionally (by E2F, p53 and Myc). Molecular targeting of EZH2, as well as HDAC and DNMT, provides important lines for the development of therapeutic strategies with which to target EZH2-high tumors such as late-stage metastatic PC (Fig. 2) (64).

Moison et al (68) found that RAR $\beta$, a TSG frequently silenced in PC, was hypermethylated in all studied prostate tumors and methylation levels were positively correlated with H3K27me3 enrichments. Thus, using bisulfite conversion and pyrosequencing of immunoprecipitated H3K27me3 chromatin, they demonstrated that DNA methylation and polycomb repression co-exist in vivo at this locus. They found this repressive association in $6 / 6$ patient tumor samples of different Gleason score, suggesting a strong interplay of DNA methylation and EZH 2 to silence $\mathrm{RAR} \beta$ during prostate tumorigenesis.

Cyclin-dependent kinases 1 and 2 (CDK1 and CDK2) phosphorylate threonine at position 350 (T350) of the EZH2 histone methyltransferase, which via SET domain (histone methyltransferase domain), catalyzes trimethylation of lysine at position 27 of histone $\mathrm{H} 3$ (H3K27me3). EZH2 phosphorylation at T350 neither affects the assembly of the PRC2 complex nor the intrinsic HMTase activity of PRC2. Phosphorylation at T350 is important for the recruitment of EZH2 to the promoters of its target genes. Trimethylated lysine residue at position 27 of histone $\mathrm{H} 3$ (H3K27me3) carried by the EZH2 protein, correlates with silencing of expression of the SLIT2 gene (Slit homolog 2; SLIT2) in most cases of metastatic PC $(69,70)$.

In PC, enhanced transcription of the EZH2 gene was observed, resulting in an increased level of methylation of the lysine residue at position 27 of histone $\mathrm{H} 3$ (H3K27me), which inhibits the expression of TSGs, such as DAB2 protein interaction $(D A B 2 I P)$, adrenoceptor $\beta 2(A D R \beta 2)$ and $C D H 1$. Epigenetic silencing of uppressor genes was found to lead to the activation of the RAS proto-oncogene and the gene encoding the nuclear transcription factor $-\kappa \mathrm{B}(\mathrm{NF}-\kappa \mathrm{B})$, which contributes to increased proliferation and migration of tumor cells. An increase in the EZH2 expression level was found to correlate with the development of PC and may indicate an aggressive nature of cancer. In the presence of an inhibitor of CDK1/2 and EZH2/T350, 3-dezaneplanocin A (DZNeP), a decrease in $\mathrm{H} 4 \mathrm{~K} 20$ followed by an increase in expression of TSGs, and subsequent blocking of the growth and invasion of PC cells were observed (Fig. 3) $(8,69)$.

Antagonists of polycomb proteins are trithorax group (TrxG) proteins, which prevent the inhibition of transcription, resulting in the relaxation of chromatin and a consequent increase in access of transcriptional activators. TrxGs include both ATP-dependent chromatin remodeling factors and histone modifiers. Histone modifier TrxGs in mammals are grouped into 3 major complexes: complex protein associated with SET domain (COMPASS), COMPASS-like and ASH (absent small and homeotic discs). COMPASS contains a histone methyltransferase domain, which is shared with PRC2. COMPASS mediates H3K4me, unlike PRC2. COMPASS-like complexes also display the SET domain, which is used to silence a more restricted group of genes. Through H4K16 acetylation, COMPASS-like can also activate gene expression. This complex is also able to demethylate H3K27me3, depending on subunit composition thereby directly counteracting PRC2. ASH1 protein can catalyze H3K36me3 giving a signal for activation $(66,71)$.

\section{Conclusion}

Epigenetics is the study of the modification of DNA and associated proteins without changing the nucleotide sequence. DNA methylation, histone modification, nucleosome remodeling, and RNA-mediated targeting regulate many biological processes that play an important role in normal cell function, and trends occurring in the process of carcinogenesis. These steps result in changes in gene expression and disruption of cellular processes, initiating the promotion of the development of cancer, including PC. The most common epigenetic changes used as biomarkers of cancer are DNA methylation and histone modifications.

\section{References}

1. Damaschke NA, Yang B, Bhusari S, Svaren JP and Jarrard DF: Epigenetic susceptibility factors for prostate cancer with aging. Prostate 73: 1721-1730, 2013.

2. Willard SS and Koochekpour S: Regulators of gene expression as biomarkers for prostate cancer. Am J Cancer Res 2: 620-657, 2012.

3. Chin SP, Dickinson JL and Holloway AF: Epigenetic regulation of prostate cancer. Clin Epigenetics 2: 151-169, 2011. 
4. Day TK and Bianco-Miotto T: Common gene pathways and families altered by DNA methylation in breast and prostate cancers. Endocr Relat Cancer 20: R215-R232, 2013.

5. Majumdar S, Buckles E, Estrada J and Koochekpour S: Aberrant DNA methylation and prostate cancer. Curr Genomics 12: 486-505, 2011.

6. Subramaniam D, Thombre R, Dhar A and Anant S: DNA methyltransferases: A novel target for prevention and therapy. Front Oncol 4: 80, 2014.

7. Buck-Koehntop BA and Defossez PA: On how mammalian transcription factors recognize methylated DNA. Epigenetics 8 : 131-137, 2013.

8. Albany C, Alva AS, Aparicio AM, Singal R, Yellapragada S, Sonpavde G and Hahn NM: Epigenetics in prostate cancer. Prostate Cancer 2011: 580318, 2011.

9. Yang M and Park JY: DNA methylation in promoter region as biomarkers in prostate cancer. Methods Mol Biol 863: 67-109, 2012.

10. Ashour N, Angulo JC, Andrés G, Alelú R, González-Corpas A Toledo MV, Rodríguez-Barbero JM, López JI, SánchezChapado $\mathrm{M}$ and Ropero S: A DNA hypermethylation profile reveals new potential biomarkers for prostate cancer diagnosis and prognosis. Prostate 74: 1171-1182, 2014.

11. Gonzalgo ML, Pavlovich CP, Lee SM and Nelson WG: Prostate cancer detection by GSTP1 methylation analysis of postbiopsy urine specimens. Clin Cancer Res 9: 2673-2677, 2003.

12. Rouprêt M, Hupertan V, Yates DR, Catto JW, Rehman I, Meuth M, Ricci S, Lacave R, Cancel-Tassin G, de la Taille A, et al: Molecular detection of localized prostate cancer using quantitative methylation-specific PCR on urinary cells obtained following prostate massage. Clin Cancer Res 13: 1720-1725, 2007.

13. Dumache R, Puiu M, Motoc M, Vernic C and Dumitrascu V: Prostate cancer molecular detection in plasma samples by glutathione S-transferase P1 (GSTP1) methylation analysis. Clin Lab 60: 847-852, 2014.

14. Bastian PJ, Palapattu GS, Lin X, Yegnasubramanian S, Mangold LA, Trock B, Eisenberger MA, Partin AW and Nelson WG: Preoperative serum DNA GSTP1 CpG island hypermethylation and the risk of early prostate-specific antigen recurrence following radical prostatectomy. Clin Cancer Res 11: 4037-4043, 2005.

15. Reibenwein J, Pils D, Horak P, Tomicek B, Goldner G, Worel N, Elandt K and Krainer M: Promoter hypermethylation of GSTP1, $\mathrm{AR}$, and 14-3-3sigma in serum of prostate cancer patients and its clinical relevance. Prostate 67: 427-432, 2007.

16. Mahon KL, Qu W, Devaney J, Paul C, Castillo L, Wykes RJ, Chatfield MD, Boyer MJ, Stockler MR, Marx G, et al; PRIMe consortium: Methylated Glutathione S-transferase 1 (mGSTP1) is a potential plasma free DNA epigenetic marker of prognosis and response to chemotherapy in castrate-resistant prostate cancer. Br J Cancer 111: 1802-1809, 2014.

17. Kang GH, Lee S, Lee HJ and Hwang KS: Aberrant CpG island hypermethylation of multiple genes in prostate cancer and prostatic intraepithelial neoplasia. J Pathol 202: 233-240, 2004.

18. Sidhu S, Deep JS, Sobti RC, Sharma VL and Thakur H: Methylation pattern of MGMT gene in relation to age, smoking, drinking and dietary habits as epigenetic biomarker in prostate cancer patients. GEBJ 8: 1-11, 2010.

19. Tang D, Kryvenko ON, Mitrache N, Do KC, Jankowski M, Chitale DA, Trudeau S, Rundle A, Belinsky SA and Rybicki BA: Methylation of the RARB gene increases prostate cancer risk in black Americans. J Urol 190: 317-324, 2013.

20. Keil KP, Abler LL, Mehta V, Altmann HM, Laporta J, Plisch EH, Suresh M, Hernandez LL and Vezina CM: DNA methylation of E-cadherin is a priming mechanism for prostate development. Dev Biol 387: 142-153, 2014.

21. Kito H, Suzuki H, Ichikawa T, Sekita N, Kamiya N, Akakura K, Igarashi T, Nakayama T, Watanabe M, Harigaya $\mathrm{K}$, et al: Hypermethylation of the CD44 gene is associated with progression and metastasis of human prostate cancer. Prostate 49: $110-115,2001$

22. Singal R, Ferdinand L, Reis IM and Schlesselman JJ: Methylation of multiple genes in prostate cancer and the relationship with clinicopathological features of disease. Oncol Rep 12: 631-637, 2004

23. Woodson K, Hayes R, Wideroff L, Villaruz L and Tangrea J: Hypermethylation of GSTP1, CD44, and E-cadherin genes in prostate cancer among US Blacks and Whites. Prostate 55: 199-205, 2003.
24. Padar A, Sathyanarayana UG, Suzuki M, Maruyama R, Hsieh JT, Frenkel EP, Minna JD and Gazdar AF: Inactivation of cyclin D2 gene in prostate cancers by aberrant promoter methylation. Clin Cancer Res 9: 4730-4734, 2003.

25. Henrique R, Costa VL, Cerveira N, Carvalho AL, Hoque MO, Ribeiro FR, Oliveira J, Teixeira MR, Sidransky D and Jerónimo C: Hypermethylation of Cyclin D2 is associated with loss of mRNA expression and tumor development in prostate cancer. J Mol Med 84: 911-918, 2006.

26. Das PM, Ramachandran K, Vanwert J, Ferdinand L, Gopisetty G, Reis IM and Singal R: Methylation mediated silencing of TMSI/ASC gene in prostate cancer. Mol Cancer 5: 28, 2006.

27. Delgado-Cruzata L, Hruby GW, Gonzalez K, McKiernan J, Benson MC, Santella RM and Shen J: DNA methylation changes correlate with Gleason score and tumor stage in prostate cancer. DNA Cell Biol 31: 187-192, 2012.

28. Liu L, Kron KJ, Pethe VV, Demetrashvili N, Nesbitt ME, Trachtenberg J, Ozcelik H, Fleshner NE, Briollais L, van der Kwast TH, et al: Association of tissue promoter methylation levels of $A P C, T G F \beta 2, H O X D 3$ and RASSF1A with prostate cancer progression. Int J Cancer 129: 2454-2462, 2011.

29. Jerónimo C, Henrique R, Hoque MO, Ribeiro FR, Oliveira J, Fonseca D, Teixeira MR, Lopes C and Sidransky D: Quantitative RARbeta2 hypermethylation: A promising prostate cancer marker. Clin Cancer Res 10: 4010-4014, 2004.

30. Youssef EM, Chen XQ, Higuchi E, Kondo Y, Garcia-Manero G, Lotan R and Issa JP: Hypermethylation and silencing of the putative tumor suppressor Tazarotene-induced gene 1 in human cancers. Cancer Res 64: 2411-2417, 2004.

31. Zhang J, Liu L and Pfeifer GP: Methylation of the retinoid response gene TIG1 in prostate cancer correlates with methylation of the retinoic acid receptor beta gene. Oncogene 23: 2241-2249, 2004

32. Choudhury JH and Ghosh SK: Promoter hypermethylation profiling identifies subtypes of head and neck cancer with distinct viral, environmental, genetic and survival characteristics. PLoS One 10: e0129808, 2015.

33. Lin JC, Wu YC, Wu CC, Shih PY, Wang WY and Chien YC: DNA methylation markers and serum $\alpha$-fetoprotein level are prognostic factors in hepatocellular carcinoma. Ann Hepatol 14: 494-504, 2015.

34. Zhang CY, Zhao YX, Xia RH, Han J, Wang BS, Tian Z, Wang LZ, Hu YH and Li J: RASSF1A promoter hypermethylation is a strong biomarker of poor survival in patients with salivary adenoid cystic carcinoma in a Chinese population. PLoS One 9: e110159, 2014

35. Maruyama R, Toyooka S, Toyooka KO, Virmani AK, ZöchbauerMüller S, Farinas AJ, Minna JD, McConnell J, Frenkel EP and Gazdar AF: Aberrant promoter methylation profile of prostate cancers and its relationship to clinicopathological features. Clin Cancer Res 8: 514-519, 2002

36. Ge YZ, Xu LW, Jia RP, Xu Z, Feng YM, Wu R, Yu P, Zhao Y, Gui ZL, Tan SJ, et al: The association between RASSF1A promoter methylation and prostate cancer: Evidence from 19 published studies. Tumour Biol 35: 3881-3890, 2014.

37. Pellacani D, Kestoras D, Droop AP, Frame FM, Berry PA, Lawrence MG, Stower MJ, Simms MS, Mann VM, Collins AT, et al: DNA hypermethylation in prostate cancer is a consequence of aberrant epithelial differentiation and hyperproliferation. Cell Death Differ 21: 761-773, 2014

38. Florl AR, Steinhoff C, Müller M, Seifert HH, Hader C, Engers R, Ackermann R and Schulz WA: Coordinate hypermethylation at specific genes in prostate carcinoma precedes LINE-1 hypomethylation. Br J Cancer 91: 985-994, 2004.

39. Schulz WA, Elo JP, Florl AR, Pennanen S, Santourlidis S, Engers R, Buchardt M, Seifert HH and Visakorpi T: Genomewide DNA hypomethylation is associated with alterations on chromosome 8 in prostate carcinoma. Genes Chromosomes Cancer 35: 58-65, 2002.

40. Gurel B, Iwata T, Koh CM, Jenkins RB, Lan F, Van Dang C, Hicks JL, Morgan J, Cornish TC, Sutcliffe S, et al: Nuclear MYC protein overexpression is an early alteration in human prostate carcinogenesis. Mod Pathol 21: 1156-1167, 2008.

41. LeBeau AM, Sevillano N, Markham K, Winter MB, Murphy ST, Hostetter DR, West J, Lowman H, Craik CS and VanBrocklin HF: Imaging active urokinase plasminogen activator in prostate cancer. Cancer Res 75: 1225-1235, 2015 .

42. Li Y and Cozzi PJ: Targeting uPA/uPAR in prostate cancer. Cancer Treat Rev 33: 521-527, 2007. 
43. Ogishima T, Shiina H, Breault JE, Tabatabai L, Bassett WW, Enokida H, Li LC, Kawakami T, Urakami S, Ribeiro-Filho LA, et al: Increased heparanase expression is caused by promoter hypomethylation and up-regulation of transcriptional factor early growth response-1 in human prostate cancer. Clin Cancer Res 11: 1028-1036, 2005.

44. Tokizane T, Shiina H, Igawa M, Enokida H, Urakami S, Kawakami T, Ogishima T, Okino ST, Li LC, Tanaka Y, et al: Cytochrome $P 4501 \mathrm{~B} 1$ is overexpressed and regulated by hypomethylation in prostate cancer. Clin Cancer Res 11: 5793-5801, 2005 .

45. Wang Q, Williamson M, Bott S, Brookman-Amissah N, Freeman A, Nariculam J, Hubank MJ, Ahmed A and Masters JR: Hypomethylation of WNT5A, CRIP1 and S100P in prostate cancer. Oncogene 26: 6560-6565, 2007.

46. Shojima K, Sato A, Hanaki H, Tsujimoto I, Nakamura M, Hattori K, Sato Y, Dohi K, Hirata M, Yamamoto H, et al: Wnt5a promotes cancer cell invasion and proliferation by receptormediated endocytosis-dependent and -independent mechanisms, respectively. Sci Rep 5: 8042, 2015.

47. Yamamoto H, Oue N, Sato A, Hasegawa Y, Yamamoto H, Matsubara A, Yasui W and Kikuchi A: Wnt5a signaling is involved in the aggressiveness of prostate cancer and expression of metalloproteinase. Oncogene 29: 2036-2046, 2010.

48. Basu GD, Azorsa DO, Kiefer JA, Rojas AM, Tuzmen S, Barrett MT, Trent JM, Kallioniemi O and Mousses S: Functional evidence implicating S100P in prostate cancer progression. Int J Cancer 123: 330-339, 2008

49. Lambropoulou M, Deftereou TE, Kynigopoulos S, Patsias A, Anagnostopoulos C, Alexiadis G, Kotini A, Tsaroucha A, Nikolaidou C, Kiziridou A, et al: Co-expression of galectin-3 and CRIP-1 in endometrial cancer: Prognostic value and patient survival. Med Oncol 33: 8, 2016.

50. Ludyga N, Englert S, Pflieger K, Rauser S, Braselmann H, Walch A, Auer G, Höfler H and Aubele M: The impact of cysteine-rich intestinal protein 1 (CRIP1) in human breast cancer. Mol Cancer 12: 28, 2013.

51. Chervona $\mathrm{Y}$ and Costa M: Histone modifications and cancer: Biomarkers of prognosis? Am J Cancer Res 2: 589-597, 2012

52. Kurdistani SK: Histone modifications in cancer biology and prognosis. Prog Drug Res 67: 91-106, 2011.

53. Chen S and Sang N: Histone deacetylase inhibitors: The epigenetic therapeutics that repress hypoxia-inducible factors. J Biomed Biotechnol 2011: 197946, 2011.

54. Crea F, Clermont PL, Mai A and Helgason CD: Histone modifications, stem cells and prostate cancer. Curr Pharm Des 20 1687-1697, 2014.

55. Cohen I, Poręba E, Kamieniarz K and Schneider R: Histone modifiers in cancer: Friends or foes? Genes Cancer 2: 631-647, 2011.

56. Sawicka A and Seiser C: Histone $\mathrm{H} 3$ phosphorylation - a versatile chromatin modification for different occasions. Biochimie 94 2193-2201, 2012

57. Nanni S, Priolo C, Grasselli A, D'Eletto M, Merola R, Moretti F, Gallucci M, De Carli P, Sentinelli S, Cianciulli AM, et al: Epithelial-restricted gene profile of primary cultures from human prostate tumors: A molecular approach to predict clinical behavior of prostate cancer. Mol Cancer Res 4: 79-92, 2006.

58. Sedelnikova OA and Bonner WM: GammaH2AX in cancer cells: A potential biomarker for cancer diagnostics, prediction and recurrence. Cell Cycle 5: 2909-2913, 2006.

59. Shaheen FS, Znojek P, Fisher A, Webster M, Plummer R, Gaughan L, Smith GC, Leung HY, Curtin NJ and Robson CN: Targeting the DNA double strand break repair machinery in prostate cancer. PLoS One 6: e20311, 2011.

60. Baptista T, Graça I, Sousa EJ, Oliveira AI, Costa NR, CostaPinheiro P, Amado F, Henrique R and Jerónimo C: Regulation of histone H2A.Z expression is mediated by sirtuin 1 in prostate cancer. Oncotarget 4: 1673-1685, 2013.

61. Monteiro FL, Baptista T, Amado F, Vitorino R, Jerónimo C and Helguero LA: Expression and functionality of histone $\mathrm{H} 2 \mathrm{~A}$ variants in cancer. Oncotarget 5: 3428-3443, 2014.

62. Nowak M, Svensson MA, Carlsson J, Vogel W, Kebschull M, Wernert N, Kristiansen G, Andrén O, Braun M and Perner S: Prognostic significance of phospho-histone H3 in prostate carcinoma. World J Urol 32: 703-707, 2014.

63. Henrique R, Oliveira AI, Costa VL, Baptista T, Martins AT, Morais A, Oliveira $\mathrm{J}$ and Jerónimo C: Epigenetic regulation of $M D R 1$ gene through post-translational histone modifications in prostate cancer. BMC Genomics 14: 898, 2013.
64. Yang YA and Yu J: EZH2, an epigenetic driver of prostate cancer. Protein Cell 4: 331-341, 2013.

65. Schwartz YB and Pirrotta V: A new world of Polycombs: Unexpected partnerships and emerging functions. Nat Rev Genet 14: 853-864, 2013.

66. Piunti A and Shilatifard A: Epigenetic balance of gene expression by Polycomb and COMPASS families. Science 352: aad9780, 2016.

67. Wang QT: Epigenetic regulation of cardiac development and function by polycomb group and trithorax group proteins. Dev Dyn 241: 1021-1033, 2012.

68. Moison C, Senamaud-Beaufort C, Fourrière L, Champion C, Ceccaldi A, Lacomme S, Daunay A, Tost J, Arimondo PB and Guieysse-Peugeot AL: DNA methylation associated with polycomb repression in retinoic acid receptor $\beta$ silencing. FASEB J 27: 1468-1478, 2013.

69. Simon JA and Lange CA: Roles of the EZH2 histone methyltransferase in cancer epigenetics. Mutat Res 647: 21-29, 2008.

70. Zeng X, Chen S and Huang H: Phosphorylation of EZH2 by CDK1 and CDK2: A possible regulatory mechanism of transmission of the $\mathrm{H} 3 \mathrm{~K} 27 \mathrm{me} 3$ epigenetic mark through cell divisions. Cell Cycle 10: 579-583, 2011.

71. Clermont PL, Crea F and Helgason CD: Trithorax Genes in Prostate Cancer. In: Advances in Prostate Cancer. Hamilton G (ed). InTech, Croatia, pp541-564, 2013.

72. Daniunaite K, Jarmalaite S, Kalinauskaite N, Petroska D, Laurinavicius A, Lazutka JR and Jankevicius F: Prognostic value of RASSF1 promoter methylation in prostate cancer. J Urol 192: $1849-1855,2014$

73. Gurioli G, Salvi S, Martignano F, Foca F, Gunelli R, Costantini M, Cicchetti G, De Giorgi U, Sbarba PD, Calistri D, et al: Methylation pattern analysis in prostate cancer tissue: Identification of biomarkers using an MS-MLPA approach. J Transl Med 14: 249, 2016.

74. Ikromov O, Alkamal I, Magheli A, Ratert N, Sendeski M, Miller K, Krause $\mathrm{H}$ and Kempkensteffen C: Functional epigenetic analysis of prostate carcinoma: A role for seryl-tRNA synthetase? J Biomark 2014: 362164, 2014.

75. Litovkin K, Van Eynde A, Joniau S, Lerut E, Laenen A Gevaert T, Gevaert O, Spahn M, Kneitz B, Gramme P, et al: DNA methylation-guided prediction of clinical failure in high-risk prostate cancer. PLoS One 10: e0130651, 2015.

76. Moritz R, Ellinger J, Nuhn P, Haese A, Müller SC, Graefen M, Schlomm T and Bastian PJ: DNA hypermethylation as a predictor of PSA recurrence in patients with low- and intermediate-grade prostate cancer. Anticancer Res 33: 5249-5254, 2013.

77. Serenaite I, Daniunaite K, Jankevicius F, Laurinavicius A, Petroska D, Lazutka JR and Jarmalaite S: Heterogeneity of DNA methylation in multifocal prostate cancer. Virchows Arch 466: 53-59, 2015.

78. Tan HL, Haffner MC, Esopi DM, Vaghasia AM, Giannico GA, Ross HM, Ghosh S, Hicks JL, Zheng Q, Sangoi AR, et al: Prostate adenocarcinomas aberrantly expressing p63 are molecularly distinct from usual-type prostatic adenocarcinomas. Mod Pathol 28: 446-456, 2015.

79. Tsvetkova A, Todorova A, Todorov T, Georgiev G, Drandarska I and Mitev V: Molecular and clinicopathological aspects of prostate cancer in Bulgarian probands. Pathol Oncol Res 21: 969-976, 2015

80. Yoon HY, Kim SK, Kim YW, Kang HW, Lee SC, Ryu KH, Shon HS, Kim WJ and Kim YJ: Combined hypermethylation of APC and GSTP1 as a molecular marker for prostate cancer: Quantitative pyrosequencing analysis. J Biomol Screen 17: 987-992, 2012

81. Yoon HY, Kim YW, Kang HW, Kim WT, Yun SJ, Lee SC, Kim WJ and Kim YJ: DNA methylation of GSTP1 in human prostate tissues: Pyrosequencing analysis. Korean J Urol 53: 200-205, 2012.

82. Zhang W, Jiao H, Zhang X, Zhao R, Wang F, He W, Zong H, Fan Q and Wang L: Correlation between the expression of DNMT1, and GSTP1 and APC, and the methylation status of GSTP1 and APC in association with their clinical significance in prostate cancer. Mol Med Rep 12: 141-146, 2015.

83. Bastian PJ, Ellinger J, Heukamp LC, Kahl P, Müller SC and von Rücker A: Prognostic value of $\mathrm{CpG}$ island hypermethylation at PTGS2, RAR-beta, EDNRB, and other gene loci in patients undergoing radical prostatectomy. Eur Urol 51: 665-674, discussion 674, 2007.

84. Müller A and Florek M: 5-Azacytidine/Azacitidine. Recent Results Cancer Res 184: 159-170, 2010. 
85. Yoon HY, Kim YW, Kang HW, Kim WT, Yun SJ, Lee SC, Kim WJ and Kim YJ: Pyrosequencing analysis of APC methylation level in human prostate tissues: A molecular marker for prostate cancer. Korean J Urol 54: 194-198, 2013.

86. Yaqinuddin A, Qureshi SA, Pervez S, Bashir MU, Nazir R and Abbas F: Frequent DNA hypermethylation at the RASSF1A and $A P C$ gene loci in prostate cancer patients of Pakistani Origin. ISRN Urol 2013: 627249, 2013.

87. Olkhov-Mitsel E, Zdravic D, Kron K, van der Kwast T, Fleshner N and Bapat B: Novel multiplex MethyLight protocol for detection of DNA methylation in patient tissues and bodily fluids. Sci Rep 4: 4432, 2014.
88. Pakneshan P, Szyf M and Rabbani SA: Hypomethylation of urokinase (uPA) promoter in breast and prostate cancer: Prognostic and therapeutic implications. Curr Cancer Drug Targets 5: 471-488, 2005.

89. Hagelgans A, Menschikowski M, Fuessel S, Nacke B, Arneth BM, Wirth MP and Siegert G: Deregulated expression of urokinase and its inhibitor type 1 in prostate cancer cells: Role of epigenetic mechanisms. Exp Mol Pathol 94: 458-465, 2013. 